\title{
Timing of Target Discrimination in Human Frontal Eye Fields
}

\author{
Jacinta O'Shea $^{1}$, Neil G. Muggleton ${ }^{1}$, Alan Cowey ${ }^{1}$, and Vincent Walsh ${ }^{2}$
}

\begin{abstract}
Frontal eye field (FEF) neurons discharge in response to behaviorally relevant stimuli that are potential targets for saccades. Distinct visual and motor processes have been dissociated in the FEF of macaque monkeys, but little is known about the visual processing capacity of FEF in humans. We used double-pulse transcranial magnetic stimulation [(d)TMS] to investigate the timing of target discrimination during visual conjunction search. We applied dual TMS pulses separated by $40 \mathrm{msec}$ over the right FEF and vertex. These were applied in five timing conditions to
\end{abstract}

\section{INTRODUCTION}

The frontal eye fields (FEFs), in the rostral arch of the arcuate sulcus in the macaque monkey (BA 8/6) (Bruce, Goldberg, Bushnell, \& Stanton, 1985), have an important role in converting the outcome of visual processing into eye movement commands. However, recent findings have challenged the characterization of FEF function solely in terms of oculomotor control (for reviews, see Schall \& Thompson, 1999; Schall \& Bichot, 1998).

FEF neurons exhibit response latencies in the same 40-80 msec range as early sensory visual areas V1, V2, V4, MT, and MST (Schmolesky et al., 1998; Nowak \& Bullier, 1997), while the discovery of feedforward connectivity between FEF and V4 has redefined the position of FEF in the visual processing hierarchy (Barone, Batardiere, Knoblaunch, \& Kennedy, 2000). Moreover, single-unit data have demonstrated that FEF neurons play a perceptual role in visual processing, independently of issuing saccade commands (Thompson, Bichot, \& Schall, 1997).

Using feature (Thompson, Hanes, Bichot, \& Schall, 1996) and conjunction (Bichot, Thompson, Chenchal Rao, \& Schall, 2001) search tasks, Schall and colleagues have dissociated two processing operations in FEF: target selection by FEF visual neurons and saccade programming by FEF movement neurons. FEF visual neurons do not respond selectively to particular physical visual attributes (Goldberg \& Segraves, 1989; Mohler,

${ }^{1}$ University of Oxford, ${ }^{2}$ University College London sample separate time windows within the first $200 \mathrm{msec}$ of visual processing. (d)TMS impaired search performance, reflected in reduced $d^{\prime}$ scores. This effect was limited to a time window between 40 and $80 \mathrm{msec}$ after search array onset. These parameters correspond with single-cell activity in FEF that predicts monkeys' behavioral reports on hit, miss, false alarm, and correct rejection trials. Our findings demonstrate a crucial early role for human FEF in visual target discrimination that is independent of saccade programming.

Goldberg, \& Wurtz, 1973). Instead, they respond to behaviorally relevant stimuli, and have been described as computing a saliency map which encodes targets for potential saccades (Schall \& Bichot, 1998). The initial visual response (50 msec poststimulus) is nonselective, but by about 100-120 msec, FEF visual neurons can distinguish with 95\% reliability targets from distractors in their receptive fields (Bichot, Thompson, et al., 2001). Distractor-related activity is suppressed, while targetrelated activity evolves to signal the spatial location of the stimulus (Schall, Morel, King, \& Bullier, 1995). FEF movement neurons do not respond to visual stimulation, but fire before and during saccades, signaling whether and when to make a saccade (Hanes \& Schall, 1995). Target discrimination occurs independently of saccade programming. The timing of the discrimination process does not predict the variability of saccadic reaction times and target discrimination occurs whether or not monkeys proceed to saccade to that target (Murthy, Thompson, \& Schall, 2001).

In human imaging studies, the FEFs are commonly activated in orienting paradigms whether or not an eye movement is required. In the latter case, this activity is commonly interpreted in terms of the premotor theory of attention (Rizzolatti, Riggio, Dascola, \& Umilta, 1987). FEF activation is attributed to the generation of saccade programs which are not overtly executed, rather than to visual analytic processes in the FEF (see, however, Donner et al., 2000). To date, only three published studies have directly addressed the perceptual role of human FEF independently of eye movements-one using intracranial visual-evoked potentials and two using 
transcranial magnetic stimulation (TMS). These studies have reported roles for the FEF in contralateral visual stimulus analysis (Blanke et al., 1999), preparatory vision (Grosbras \& Paus, 2002), and target detection in conjunction visual search (Muggleton, Juan, Cowey, \& Walsh, 2003).

In this study, we exploited the temporal resolution of TMS to test the hypothesis that, as in the macaque, target discrimination processes occur early in human FEF. To decouple perceptual from oculomotor processes, we used a conjunction search task in which eye movements were not required (see Figure 1A). We presented search arrays briefly enough to ensure subjects could not saccade to search elements and we monitored fixation. A staircase procedure determined array duration for each subject, supporting performance at $75 \%$ accuracy. In a pilot experiment (see Methods), we used repetitive-pulse (r)TMS to gather preliminary evidence for an early profile of TMS interference. On the basis of these data, we expected an effect of TMS during the first $100 \mathrm{msec}$ of stimulus processing. In the main experiment, we used double-pulse TMS [(d)TMS] to test more precisely our hypothesis of a critical early period of perceptual processing in FEF. We found an early disruptive effect

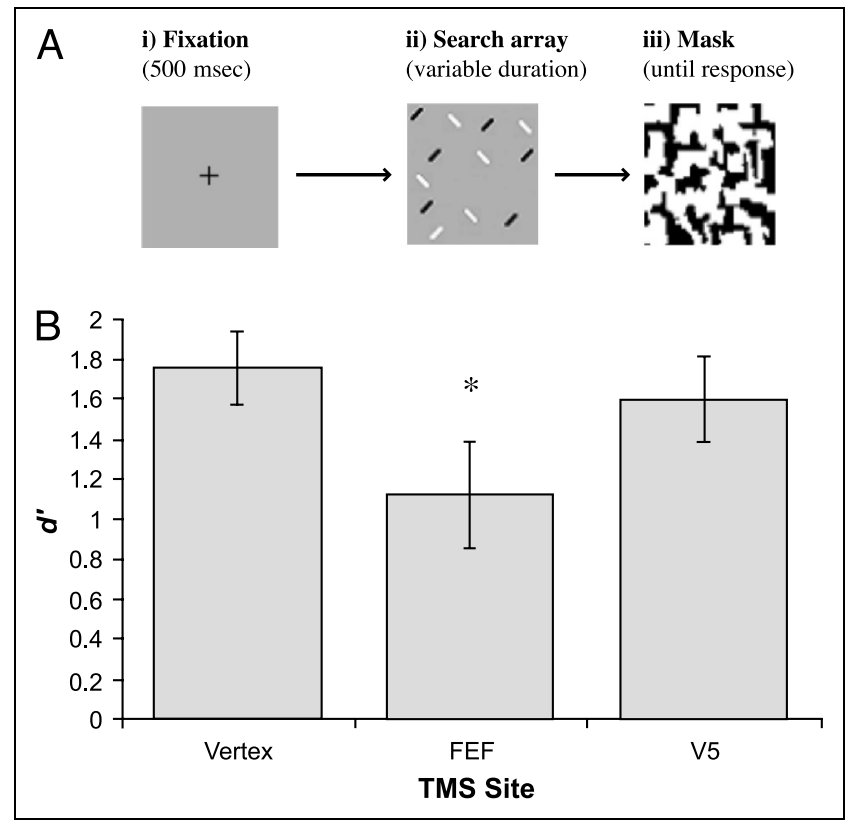

Figure 1. (A) Stimuli and sequence of events in a single trial. White and black lines represent the purple and pink diagonal lines used in the experiment. The target was always a purple diagonal of the opposite orientation. A trial began with central fixation (i), followed by the search array, for a duration determined individually for each subject (ii). The array was then masked until the subject signaled whether the target was present or absent (iii). (B) Effect of TMS over FEF on search performance in the pilot experiment. Search performance was impaired when TMS was applied over the right FEF, but not over V5 or the vertex. TMS significantly reduced $d^{\prime}$ (* refers to planned comparison with the vertex, $p=.026)(n=8)$.
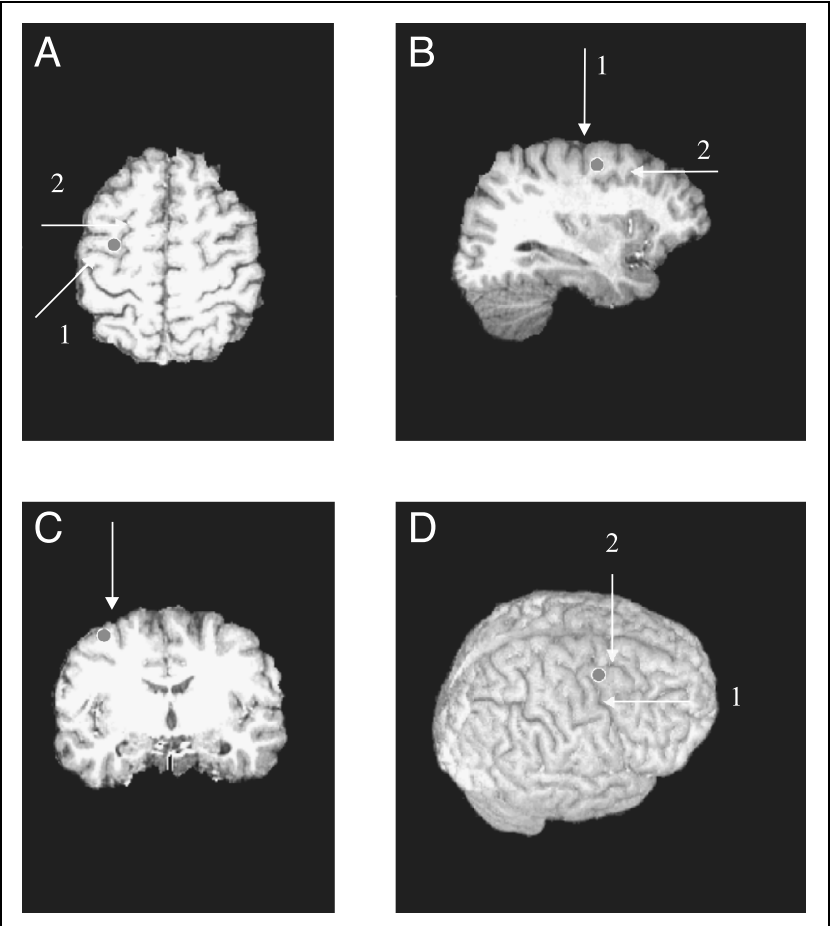

Figure 2. FEF localization. The figure shows the anatomical landmarks used in combination with frameless stereotaxy to localize the FEF on each individual subject's MRI. The mean point of FEF stimulation is marked by the filled white circle. (A) Transverse section showing FEF location at the caudal end of the middle frontal gyrus, at the junction of the precentral sulcus (1) and superior frontal sulcus (2). (B) Sagittal section showing FEF location at the level of the insula. (C) Coronal section. Arrow indicates superior frontal sulcus. (D) 3-D rendered image showing FEF location at the junction of the precentral sulcus (1) and superior frontal sulcus (2).

of (d)TMS which, we argue, reflects target discrimination processes in human FEF and not latent saccade programming.

\section{RESULTS}

Results from a pilot study replicated our previous finding that repetitive-pulse TMS (10 Hz, $500 \mathrm{msec})$ over the right FEF degrades conjunction search performance $\left(d^{\prime}\right)$ (Muggleton et al., 2003) (see Figure 1B). The data suggested that this decrement was greater when stimulation occurred early in stimulus processing. Based on this, we applied dual TMS pulses 40 msec apart over the right FEF (see Figure 2) and the vertex (control) to sample separate time windows within the first $200 \mathrm{msec}$ of stimulus processing. In the first three conditions, dual pulses were applied at: 0/40 msec; $40 / 80 \mathrm{msec}$ and $80 / 120$ msec after stimulus onset; in the last two conditions, dual pulses were applied during the last $40 \mathrm{msec}$ prior to each subject's visual threshold ("pre-threshold") and during the first $40 \mathrm{msec}$ after threshold ("postthreshold"). For example, if a subject's threshold was $150 \mathrm{msec}$, dual pulses were applied at 100/140 and at 


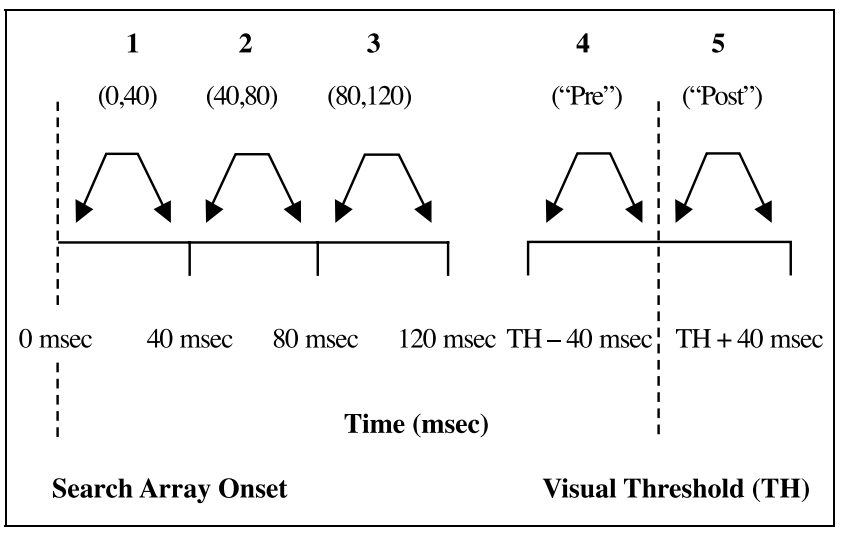

Figure 3. Timing of (d)TMS application. The figure shows the timing of first and second TMS pulses applied in five experimental conditions. The timing of the first three conditions was determined relative to the onset of the search array, and these were identical for each subject. The last two conditions were determined relative to each individual's visual threshold and differed across subjects.

160/200 msec, respectively (Figure 3). The mean visual threshold for viewing the search arrays was $178 \mathrm{msec}$ (range: 150-200 msec). A MANOVA revealed a significant effect in the $40 / 80$ msec condition only $[F(1)=4.762$, $p=.044]$. TMS applied over the FEF at $40 / 80 \mathrm{msec}$ significantly reduced subjects' perceptual sensitivity (FEF 40/80 mean $d^{\prime}=1.132$, $\mathrm{SE}=0.133$; vertex $40 / 80$ mean $d^{\prime}=1.543, \mathrm{SE}=0.133$ ) (Figure 4). A follow-up MANOVA on trials classified as hits, misses, false alarms, and correct rejections revealed no significant effects. Log $\beta$ measures showed a tendency towards "target absent" responses that did not, however, differ significantly across conditions.

\section{DISCUSSION}

We examined the timing and functional role of human FEFs in visual search to test whether findings from single-unit recordings in macaques are applicable to humans. Using (d)TMS, we tested the hypothesis that FEF neurons play a critical role in visual search performance when eye movements are not required. Target discrimination activity was decoupled from saccade programming in the FEF by using brief displays to prevent saccades and by monitoring fixation. Our results confirm an important early role for human FEF in search performance. The temporal profile of TMS interference coincides with neurophysiological data. (d)TMS over the FEF significantly degraded stimulus discriminability $\left(d^{\prime}\right)$ in the $40 / 80 \mathrm{msec}$ condition only. This accords with single-unit data from a masking study which showed that activity in FEF visual neurons 60-90 msec after visual stimulus onset predicted monkeys' perceptual reports (Thompson \& Schall, 1999). During that period, FEF signal amplitude correlated with monkeys' perceptual judgements on hit, miss, false alarm, and correct rejection trials.

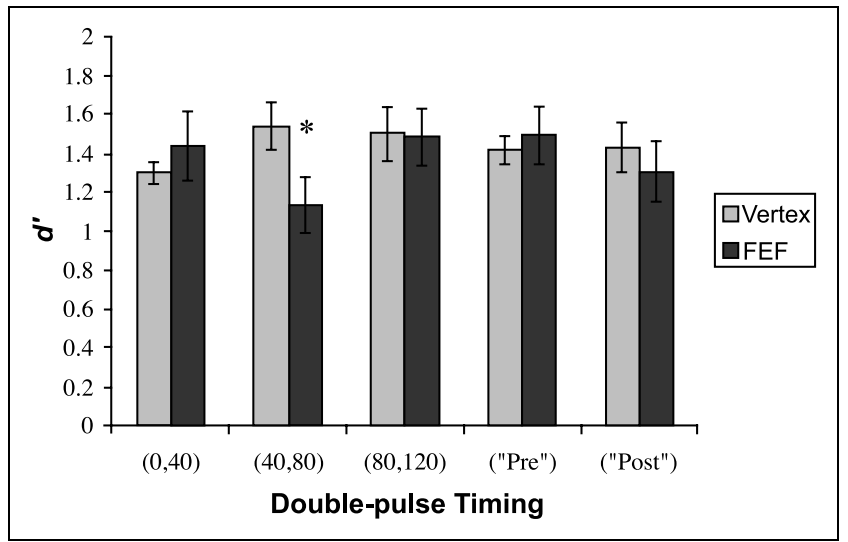

Figure 4. Effect of (d)TMS over the FEF on search performance. (d)TMS applied over the FEF at 40/80 msec significantly reduced $d^{\prime}$ (" refers to MANOVA with "TMS Time" and "TMS Site" [vertex, FEF] as factors, $p<.05)(n=9)$.

Under normal circumstances, visual scenes are inspected by cycles of stimulus fixation and analysis, followed by saccades that direct gaze to subsequent targets in the visual scene. Minimum estimates of the time required to perform these operations suggest that perceptual processing requires approximately $100 \mathrm{msec}$ (Salthouse, Ellis, Diener, \& Somberg, 1981), whereas saccade programming requires 100-150 msec (Becker \& Jurgens, 1979; Lisberger, Fuchs, King, \& Evinger, 1975). Our argument that early TMS interference reflects disruption of target discrimination, rather than saccade programming, seems to imply there are temporally discrete stages of perception and saccade programming. However, there is evidence that perceptual processing and saccade programming proceed in parallel (McPeek, Han, \& Keller, 2003; McPeek \& Keller, 2002). Moreover, it has been shown that FEF movement-related neurons are modulated by stimulus distractor properties, suggesting a model of continuous information transfer between FEF visual and motor neurons (Bichot, Chenchal Rao, \& Schall, 2001). Hence, despite the fact that eye movements were not required in our experiment, the question arises whether we have disrupted latent saccade programming. We think this unlikely, although not impossible, because the effective time of (d)TMS interference was early (40-80 msec), about $100 \mathrm{msec}$ earlier than the mean visual threshold (178 msec). Because the effect of a TMS pulse on neural firing is immediate, if our results were due to disruption of latent saccade programs, then we would expect interference to occur later, closer to the time of saccade evolution (e.g., in the $80 / 120$ or $120 / 160$ time bin). Significantly, however, there was no effect of (d)TMS in any of the later time bins. Moreover, although it is clear that disrupting visual discrimination should affect saccade programming, it is difficult to explain how disrupting saccade programming should affect visual discrimination $\left(d^{\prime}\right)$. In light of this, we believe our 
explanation in terms of target discrimination is more parsimonious than an explanation based on latent saccade programming.

Although the timing data we report are close to those reported from studies of single units in monkeys, they do not correspond exactly. Typically, target discrimination in single units evolves over 50-70 msec after the onset of a visual search stimulus and normally peaks at 100-120 msec, by which time FEF neurons can distinguish targets from distractors with 95\% reliability (Bichot, Thompson, et al., 2001). Further, the peak of perceptual processing has been shown to occur later as task difficulty is increased. Hence, target discrimination tends to occur earlier during feature than conjunction search (Bichot, Chenchal Rao, et al., 2001). Our combination of a conjunction search paradigm and an early disruptive effect thus seems to pose an interpretative problem. We offer the following observations in an attempt to address this. First, Bichot, Chenchal Rao, et al. (2001, Figure 2, p. 716) provided evidence that FEF neurons can exhibit target discrimination activity during conjunction search that is as early as that typically recorded during feature search. Second, it is important to note that the search paradigms used in the work on monkeys and in our TMS study were different. Our search displays were foveal, whereas the monkey displays were peripheral, a factor which might contribute to the early timing of our effect. Third, the repetition of the same target/distractor combination likely resulted in feature priming across the 10 blocks of 80 trials in our experiment (Maljkovic \& Nakayama, 1994). Such priming has been shown to produce earlier target discrimination peaks in monkey FEF (Bichot \& Schall, 2002). Finally, species differences, including brain sizes, should not be dismissed in considering the lack of precise concordance between the timing of our TMS effect and the mean reported peak of perceptual processing in monkey FEF.

Based on the close temporal correlation between our data and single-unit data (Thompson \& Schall, 1999; Nowak \& Bullier, 1997; for a discussion of TMS and single-unit timing correspondence, see Walsh \& PascualLeone, 2003), we have suggested that the perceptual impairments produced by TMS reflect disruption of target discrimination processes computed within the FEF. However, the target selection process manifested in the FEF is likely to be closely related to target selection observed in extrastriate areas such as V2 and V4 (Schall, 2002; Luck, Chelazzi, Hillyard, \& Desimone, 1997). The FEF sends extensive feedback projections to the extrastriate cortex (Schall, Morel, King, \& Bullier, 1995; Stanton, Bruce, \& Goldberg, 1995), and has been proposed to exert "top-down control" on these areas, such as modulating the gain of visually driven signals (Moore \& Armstrong, 2003; Moore \& Fallah, 2001). Feedback mechanisms are often proposed to explain effects that are delayed in time relative to the response onset of the cell (e. g., Lamme, 1995). However, a number of studies have shown that feedback connections are matched in conduction speed to feedforward connections (Nowak, James, \& Bullier, 1997; Girard, Hupe, \& Bullier, 2001; Hupe et al., 2001). Hence, the early timing of our effect fits with both feedforward and feedback activation of FEF, consistent with a "retroinjection" model of visual processing (Bullier, 2001).

The computational role of human FEF in vision remains to be established. Current functional sketches ascribe roles for FEF in covert orienting, visual search, saliency map formation, and oculomotor responses (Corbetta \& Shulman, 2002; Schall \& Thompson, 1999). Similar functions have been ascribed to the posterior parietal cortex (PPC) (Andersen \& Buneo, 2002; Colby \& Goldberg, 1999). The FEF and the PPC share strong reciprocal interconnections (Cavada \& Goldman-Rakic, 1989) and are both consistently activated nodes in the fronto-parietal networks associated with these functions (e.g., Donner et al., 2002). Despite these similar profiles, human imaging data are most commonly interpreted in terms of relative specialization of the FEF for overt motor-exploratory and the PPC for sensory-representational aspects of attentional tasks (Gitelman et al., 1999; Mesulam, 1981). Our results with TMS, however, indicate that FEF is involved earlier than PPC in visual conjunction search (Ashbridge et al., 1997). These data underline the need to distinguish the relative contributions of FEF and PPC to visual target selection.

\section{METHODS}

\section{Pilot Study}

The pilot study used the same procedures as the main experiment (for details, see below), but a different TMS protocol. Repetitive-pulse (r)TMS (10 Hz, $500 \mathrm{msec}$ ) was applied over the right FEF, right V5, and the vertex and the finding of a selective performance $\left(d^{\prime}\right)$ decrement with FEF TMS was replicated [ANOVA: $F(2)=$ 5.844, $p=.014$; see Figure 1B] (Muggleton et al., 2003). In two further conditions, TMS over the FEF began 100 or 200 msec after search array onset. The $d^{\prime}$ data from the $\mathrm{FEF}_{(0)}, \mathrm{FEF}_{(100)}$, and $\mathrm{FEF}_{(200)}$ conditions were compared against the vertex to test the hypothesis of greater performance deficits with earlier TMS application. Planned contrasts revealed a significant $d^{\prime}$ decrement only in the $\mathrm{FEF}_{(0)}$ condition $[F(1)=25.019$, $p=.004]$. Analysis of individual responses revealed a significant effect of TMS condition (vertex, $\mathrm{FEF}_{(0)}$, $\mathrm{FEF}_{(100)}, \mathrm{FEF}_{(200)}$ ) on response type (hit, miss, false alarm, correct rejection) $[F(9)=3.450, p=.003]$. TMS increased false alarms in the $\operatorname{FEF}_{(0)}[F(1)=6.960$, $p=.046]$ and $\mathrm{FEF}_{(100)}[F(1)=7.335, p=.042]$ conditions. On the basis of these results, we applied TMS throughout the first $200 \mathrm{msec}$ of stimulus process- 
ing in the main experiment and expected an effect within the first $100 \mathrm{msec}$.

\section{Subjects}

Eight subjects ( 7 men, 1 woman) participated in the pilot experiment (mean age $=27.6 \pm 4.3$ ). Nine subjects (8 men, 1 woman) completed the main experiment (mean age $=27.7 \pm 3.6$ ). Of these, four had participated in the pilot experiment. A further four subjects were discarded for reasons given below (see Task Design). All subjects were right-handed and had normal or corrected-to-normal vision. All gave informed written consent and reported an absence of any neurological condition in their known family history. All procedures were approved by the Oxford Research Ethics Committee (OxREC) and the Institute of Neurology, University College London.

\section{Visual Stimuli}

Visual search arrays were displayed on a 16-in. VDU with $100 \mathrm{~Hz}$ vertical refresh rate, controlled by a Pentium 4 $(1.7 \mathrm{GHz})$ microcomputer. E-Prime software (Psychology Software Tools, Pittsburgh, PA) controlled presentation of the search stimuli, triggering of the TMS machine and the eye tracker and also recorded subjects' responses on a keyboard. Subjects sat in a dark room $57 \mathrm{~cm}$ in front of the screen and were restricted by a forehead and chin rest. Each search array subtended $2^{\circ} \times 2^{\circ}$ of visual angle around a central fixation cross. Each array contained 12 stimuli. In the pilot experiment, these consisted of luminance-matched $\left(22 \mathrm{~cd} / \mathrm{m}^{2}\right)$ purple vertical (CIE: $x=0.217, y=0.130$ ) and green horizontal (CIE: $x=$ $0.282, y=0.589)$ lines, each subtending circa $0.23^{\circ}$ of visual angle. The target was a purple horizontal and was present in 50\% of trials. Stimulus colors were changed to avoid potential learning confounds from subjects who had participated in the pilot. In the main experiment stimuli were luminance-matched $\left(23.3 \mathrm{~cd} / \mathrm{m}^{2}\right)$ pink (CIE: $x=0.288, y=0.149$ ) and purple (CIE: $x=0.233$, $y=0.203$ ) diagonal lines in opposite orientations. Each line subtended circa $0.18^{\circ}$ of visual angle. The target was a purple diagonal sharing the same orientation as the pink diagonals and was present in 50\% of trials. The luminance of the background was uniform gray $(35.8 \mathrm{~cd} /$ $\mathrm{m}^{2}$ ). In both experiments, the stimulus mask subtended $2^{\circ} \times 2^{\circ}$ of visual angle and was composed of patches of the two stimulus colors used in that experiment.

\section{Task Design}

The task procedure has been described previously in Muggleton et al (2003) (see Figure 1). A trial began with a central fixation cross presented for $500 \mathrm{msec}$, followed by a briefly presented search array, which was then masked until the subject made a response. Subjects had to decide whether the target was present or absent and signaled their decision using a keypress. Accuracy was emphasized over speed of response. The intertrial interval was $2000 \mathrm{msec}$. Stimulus duration was determined for each subject individually, based on a staircase procedure which varied presentation time by one screen refresh (10 msec) until subjects performed at a $75 \%$ accuracy level. Subjects had to perform exactly six out of eight trials correctly on two consecutive blocks of eight trials to establish their stimulus thresholds. They then performed a block of 60 trials to determine the validity of this threshold value. When subjects scored $d^{\prime}>1.0$, they began formal trials. Performance yielding a $d^{\prime}$ score greater than or equal to 1.0 indicates reliable perceptual sensitivity (Green \& Swets, 1966). If subjects failed to achieve the $d^{\prime}$ criterion, the stimulus duration was increased by the experimenter until the criterion was reached. Block order was counterbalanced and all the above procedures were identical in both experiments.

In the pilot experiment, subjects performed five blocks of 60 trials, one for each TMS condition: vertex, V5, $\mathrm{FEF}_{(0)}, \mathrm{FEF}_{(100)}$, and $\mathrm{FEF}_{(200)}$. In the first three conditions (vertex, V5, and $\mathrm{FEF}_{(0)}$ ), TMS was applied for $500 \mathrm{msec}$ beginning at visual stimulus onset. In the latter two conditions, TMS was applied for $500 \mathrm{msec}$ beginning $100 \mathrm{msec}\left(\mathrm{FEF}_{(100)}\right)$ or $200 \mathrm{msec}\left(\mathrm{FEF}_{(200)}\right)$ after visual stimulus onset. By comparing these and the $\mathrm{FEF}_{(0)}$ condition against the vertex, the aim was to isolate different periods of FEF activity and test the relative effect of TMS in each: during the first $100 \mathrm{msec}$ of visual processing $\left(\mathrm{FEF}_{(0)}\right)$; during visual processing, but after the first $100 \mathrm{msec}\left(\mathrm{FEF}_{(100)}\right)$; and after visual processing, when subjects were no longer viewing the search array $\left(\mathrm{FEF}_{(200)}\right)$.

In the main experiment, subjects performed two blocks of 40 trials in each of five timing conditions ( 0 / 40 msec; 40/80 msec; 80/120 msec; "pre-threshold" and "post-threshold") at each TMS site (vertex and right FEF). In the first three timing conditions, dual TMS pulses were applied at: 0/40, 40/80, and 80/120 msec after stimulus onset; in the last two conditions, dual pulses were applied during the last $40 \mathrm{msec}$ below each subject's visual threshold ("pre-threshold") and during the first 40 msec above threshold ("post-threshold"). For example, if a subject's threshold was $150 \mathrm{msec}$, dual pulses were applied at 100/140 and at 160/200 msec, respectively (Figure 3). The 0/40 msec and "post-threshold" conditions were chosen as temporal limit controls to bracket the earliest and latest arrivals of retinal input to the FEF: the $0 / 40 \mathrm{msec}$ stimulation precedes the earliest onset latencies of FEF neurons (Schmolesky et al., 1998), while the "post-threshold" condition allows $40 \mathrm{msec}$ after the end of retinal stimulation. An effect of TMS was expected in the 40/80 msec condition (and possibly in the $80 / 120$ msec condition), but not in the "pre-threshold" condition. Interspersed among these experimental blocks, subjects performed four blocks in 
which TMS was not applied. If a subject's $d^{\prime}$ scores on each of these baseline blocks did not exceed 1.0, testing did not continue and the subject was excluded from the experiment. Four subjects were discounted on these grounds and the data from the remaining nine subjects were analyzed.

\section{Eye Movement Recording}

To monitor fixation and any blinks during search trials, horizontal eye movements were recorded using infrared light transducers in the Skalar IRIS 6500 system attached to the forehead rest. Signals were sampled at a rate of $1000 \mathrm{~Hz}$ by an analog-to-digital converter card (Type PCM-DAS 16d/12, Computerboards, Pittsburgh, $\mathrm{PA})$ and recorded using DASYlab 5 software on an IBM compatible PC. Eye traces were recorded for the duration of the visual stimulus on every trial and the equipment was recalibrated between blocks.

\section{Cortical Site Localization}

Based on the results of pilot data showing RT costs on visual search when TMS was applied over the right but not the left FEF (reported in Muggleton et al., 2003), the right FEF was chosen as the site of an expected TMS effect. FEF was localized for TMS using the Brainsight frameless stereotaxy system (Rogue Research, Montreal, Canada). The stimulation site was identified on each subject's T1-weighted MRI scan and was then coregistered with scalp coordinates over which TMS was applied (see Figure 2). The probabilistic location of each subject's right FEF was determined according to anatomical landmarks. Stimulation was applied over the posterior middle frontal gyrus, just rostral of the junction of the precentral sulcus and the superior frontal sulcus (Blanke et al., 2000). The site of stimulation was also referenced to each subject's motor hand area (Ro, Cheifet, Ingle, Shoup, \& Rafal, 1999; Yousry et al., 1997). Using this method, on average, TMS was applied $5 \mathrm{~cm}$ lateral of the sagittal midline and 3-4 cm rostral of each subject's motor hand area. This site corresponds well with scalp coordinates used in other TMS studies of the FEF (Leff, Scott, Rothwell, \& Wise, 2001; Wipfli et al., 2001; Muri, Hess, \& Meienberg, 1991). After registration of the MRI images to the Montreal Neurological Institute series average (Evans, Collins, \& Holmes, 1996), mean Talairach coordinates for the site stimulated were 32, -2, 61 (standard error: 1.34, 6.09, 1.55) (Talairach \& Tournoux, 1988). These coordinates correspond well with mean Talairach coordinates for the FEF derived from a review of PET imaging studies (Paus, 1996). The vertex was chosen as the principal control site for the nonspecific effects of TMS, such as somatosensory and acoustic artifacts. V5 was chosen as an additional control to demonstrate that any effects of FEF TMS on visual search are specific and not a general consequence of interference with the visual system. Vertex stimulation was applied at electrode site "Cz" according to the 10-20 International Electrode System. V5 was localized functionally using the established method of moving phosphene elicitation (Battelli, Black, \& Wray, 2002; Stewart, Battelli, Walsh, \& Cowey, 1999).

\section{Transcranial Magnetic Stimulation}

A Magstim Super Rapid machine (Magstim Company, Dyfed, UK) was used to deliver (r)TMS and (d)TMS. A series of small-diameter $(50 \mathrm{~mm})$ figure-of-eight TMS coils were used to apply stimulation over the cortical sites of interest. Coils were cooled on ice before use to prevent overheating during a block and were replaced at the end of each block. Over the FEF and the vertex, each coil was oriented parallel to the floor with the handle running in an anterior-posterior direction and was clamped in position using a mechanical arm. Over V5, each coil was oriented at a right angle with the floor. In the (r)TMS paradigm, $10 \mathrm{~Hz}$ TMS (500 $\mathrm{msec}$ ) was applied at $65 \%$ of stimulator output over the vertex and the FEF. Over V5, TMS was applied at 110\% of each subject's phosphene threshold (Stewart, Walsh, \& Rothwell, 2001). Subjects wore earplugs to attenuate the sound of the coil discharge (Pascual-Leone et al., 1993).

\section{Acknowledgments}

J. O'S. was supported by the Wellcome Trust, A. C. and N. G. M. by the Medical Research Council, and V. W. by the Royal Society. The work was further supported by a Wellcome Trust equipment grant to the Institute of Cognitive Neuroscience.

Reprint requests should be sent to Jacinta O'Shea, Department of Experimental Psychology, University of Oxford, South Parks Road, Oxford, OX1 3UD UK, or via e-mail: jacinta.oshea@ psy.ox.ac.uk.

\section{REFERENCES}

Andersen, R. A., \& Buneo, C. A. (2002). Intentional maps in posterior parietal cortex. Annual Review of Neuroscience, 25, 189-220.

Ashbridge, E., Walsh, V., \& Cowey, A. (1997). Temporal aspects of visual search studied by transcranial magnetic stimulation. Neuropsychologia, 35, 1121-1131.

Barone, P., Batardiere, A., Knoblauch, K., \& Kennedy, H. (2000). Laminar distribution of neurons in extrastriate areas projecting to visual areas V1 and V4 correlates with the hierarchical rank and indicates the operation of a distance rule. Journal of Neuroscience, 20, 3263-3281.

Battelli, L., Black, K. R., \& Wray, S. H. (2002). Transcranial magnetic stimulation of visual area V5 in migraine. Neurology, 58, 1066-1069.

Becker, W., \& Jurgens, R. (1979). An analysis of the saccadic system by means of double step stimuli. Vision Research, 19, 967-983.

Bichot, N. P., Chenchal Rao, S., \& Schall, J. D. (2001). Continuous processing in macaque frontal cortex during visual search. Neuropsychologia, 39, 972-982.

Bichot, N. P., Thompson, K. G., Chenchal Rao, S., \& Schall, J. D. 
(2001). Reliability of macaque frontal eye field neurons signalling saccade targets during visual search. Journal of Neuroscience, 21, 713-725.

Bichot, N. P., \& Schall, J. D. (2002). Priming in macaque frontal cortex during popout visual search: Feature-based facilitation and location-based inhibition of return. Journal of Neuroscience, 22, 4675-4685.

Blanke, O., Morand, S., Thut, G., Michel, C. M., Spinelli, L., Landis, T., \& Seeck, M. (1999). Visual activity in the human frontal eye field. NeuroReport, 10, 925-930.

Blanke, O., Spinelli, L., Thut, G., Michel, C. M., Perrig, S., Landis, T., \& Seeck, M. (2000). Location of the human frontal eye field as defined by electrical cortical stimulation: Anatomical, functional and electrophysiological characteristics. NeuroReport, 11, 1907-1913.

Bruce, C. J., Goldberg, M. E., Bushnell, M. C., \& Stanton, G. B. (1985). Primate frontal eye fields: II. Physiological and anatomical correlates of electrically evoked eye movements. Journal of Neurophysiology, 54, 714-734.

Bullier, J. (2001). Integrated model of visual processing. Brain Research Reviews, 36, 96-107.

Cavada, C., \& Goldman-Rakic, P. S. (1989). Posterior parietal cortex in rhesus monkey: II. Evidence for segregated corticocortical networks linking sensory and limbic areas with the frontal lobe. Journal of Computational Neurology, 287, 422-445.

Colby, C. L., \& Goldberg, M. E. (1999). Space and attention in parietal cortex. Annual Review of Neuroscience, 22, 319-349.

Corbetta, M., \& Shulman, G. L. (2002). Control of goal-directed and stimulus-driven attention in the brain. Nature Reviews Neuroscience, 3, 201-215.

Donner, T., Kettermann, A., Diesch, E., Ostendorf, F., Villringer, A., \& Brandt, S. A. (2000). Involvement of the human frontal eye field and multiple parietal areas in covert visual selection during conjunction search. European Journal of Neuroscience, 12, 3407-3414.

Donner, T. H., Kettermann, A., Diesch, E., Ostendorf, F., Villringer, A., \& Brandt, S. A. (2002). Visual feature and conjunction searches of equal difficulty engage only partially overlapping frontoparietal networks. Neuroimage, 15, $16-25$.

Evans, A. C., Collins, D. L., \& Holmes, C. J. (1996). In J. C. Mazziotta (Ed.), Brain mapping: The methods (pp. 343-361). San Diego: Academic Press.

Girard, P., Hupe, J. M., \& Bullier, J. (2001). Feedforward and feedback connections between areas V1 and V2 of the monkey have similar rapid conduction velocities. Journal of Neurophysiology, 85, 1328-1331.

Gitelman, D. R., Nobre, A. C., Parrish, T. B., LaBar, K. S., Kim, Y. H., Meyer, J. R., \& Mesulam, M. (1999). A large-scale distributed network for covert spatial attention: Further anatomical delineation based on stringent behavioural and cognitive controls. Brain, 122, 1093-1106.

Goldberg, M. E., \& Segraves, M. A. (1989). The visual and frontal cortices. Review of Oculomotor Research, 3, 283-313.

Green, D. M., \& Swets, J. A. (1996). Signal detection theory and psychophysics. New York: Wiley.

Grosbras, M. H., \& Paus, T. (2002). Transcranial magnetic stimulation of the human frontal eye field: Effects on visual perception and attention. Journal of Cognitive Neuroscience, 14, 1109-1120.

Hanes, D. P., \& Schall, J. D. (1995). Countermanding saccades in macaque. Visual Neuroscience, 12, 929-937.

Hupe, J. M., James, A. C., Girard, P., Lomber, S. G., Payne, B. R.,
\& Bullier, J. (2001). Feedback connections act on the early part of the responses in monkey visual cortex. Journal of Neurophysiology, 85, 134-145.

Lamme, V. A. (1995). The neurophysiology of figure-ground segregation in primary visual cortex. Journal of Neuroscience, 15, 1605-1615.

Leff, A. P., Scott, S. K., Rothwell, J. C., \& Wise, R. J. (2001). The planning and guiding of reading saccades: A repetitive transcranial magnetic stimulation study. Cerebral Cortex, 11, 918-923.

Lisberger, S. G., Fuchs, A. F., King, W. M., \& Evinger, L. C. (1975). Effect of mean reaction time on saccadic responses to two-step stimuli with horizontal and vertical components. Vision Research, 15, 1021-1025.

Luck, S. J., Chelazzi, L., Hillyard, S. A., \& Desimone, R. (1997). Neural mechanisms of spatial selective attention in areas V1, $\mathrm{V} 2$, and V4 of macaque visual cortex. Journal of Neurophysiology, 77, 24-42.

Maljkovic, V., \& Nakayama, K. (1994). Priming of pop-out: 1. Role of features. Memory \& Cognition, 22, 657-672.

McPeek, R. M., Han, J. H., \& Keller, E. L. (2003). Competition between saccade goals in the superior colliculus produces saccade curvature. Journal of Neurophysiology, 89, 2577-2590.

McPeek, R. M., \& Keller, E. L. (2002). Saccade target selection in the superior colliculus during a visual search task. Journal of Neurophysiology, 88, 2019-2034.

Mesulam, M. M. (1981). A cortical network for directed attention and unilateral neglect. Annals of Neurology, 10, 309-325.

Mohler, C. W., Goldberg, M. E., \& Wurtz, R. H. (1973). Visual receptive fields of frontal eye field neurons. Brain Research, 61, 385-389.

Moore, T., \& Armstrong, K. M. (2003). Selective gating of visual signals by microstimulation of frontal cortex. Nature, 421, 370-373.

Moore, T., \& Fallah, M. (2001). Control of eye movements and spatial attention. Proceedings of the National Academy of Sciences, U.S.A., 98, 1273-1276.

Muggleton, N. G., Juan, C.-H., Cowey, A., \& Walsh, V. (2003). Human Frontal Eye Fields and Visual Search. Journal of Neurophysiology, 89, 3340-3343.

Muri, R. M., Hess, C. W., \& Meienberg, O. (1991). Transcranial stimulation of the human frontal eye field by magnetic pulses. Experimental Brain Research, 86, 219-223.

Murthy, A., Thompson, K. G., \& Schall, J. D. (2001). Dynamic dissociation of visual selection from saccade programming in frontal eye field. Journal of Neurophysiology, 86, 2634-2637.

Nowak, L. G., \& Bullier, J. (1997). The timing of information transfer in the visual system. In K. S. Rockland, J. H. Kaas, \& A. Peters (Eds.), Cerebral cortex (Vol. 12, pp. 205-241). New York: Plenum Press.

Nowak, L. G., James, A. C., \& Bullier, J. (1997). Corticocortical connections between visual areas 17 and $18 \mathrm{a}$ of the rat studied in vitro: Spatial and temporal organisation of functional synaptic responses. Experimental Brain Research, 117, 219-241.

Pascual-Leone, A., Houser, C. M., Reese, K., Shotland, L. I., Grafman, J., Sato, S., Valls-Sole, J., Brasil-Neto, J. P., Wassermann, E. M., Cohen, L. G., \& Hallett, M. (1993). Safety of rapid-rate transcranial magnetic stimulation in normal volunteers. Electroencephalography and Clinical Neurophysiology, 89, 120-130.

Paus, T. (1996). Location and function of the human frontal eye-field: A selective review. Neuropsychologia, 34, 475-483.

Rizzolatti, G., Riggio, L., Dascola, I., \& Umilta, C. (1987). Reorienting attention across the horizontal and vertical 
meridians: Evidence in favor of a premotor theory of attention. Neuropsychologia, 25, 31-40.

Ro, T., Cheifet, S., Ingle, H., Shoup, R., \& Rafal, R. (1999). Localization of the human frontal eye fields and motor hand area with transcranial magnetic stimulation and magnetic resonance imaging. Neuropsychologia, 37, 225-231.

Salthouse, T. A., Ellis, C. L., Diener, D. C., \& Somberg, B. L. (1981). Stimulus processing during eye fixations. Journal of Experimental Psychology: Human Perception and Performance, 7, 611-623.

Schall, J. D. (1995). Neural basis of saccade target selection. Review of Neuroscience, 6, 63-85.

Schall, J. D. (2002). The neural selection and control of saccades by the frontal eye field. Philosophical Transactions of the Royal Society of London, B, Biological Sciences, 357, 1073-1082.

Schall, J. D., \& Bichot, N. P. (1998). Neural correlates of visual and motor decision processes. Current Opinion in Neurobiology, 8, 211-217.

Schall, J. D., Morel, A., King, D. J., \& Bullier, J. (1995). Topography of visual cortex connections with frontal eye field in macaque: Convergence and segregation of processing streams. Journal of Neuroscience, 15 , $4464-4487$.

Schall, J. D., \& Thompson, K. G. (1999). Neural selection and control of visually guided eye movements. Annual Review of Neuroscience, 22, 241-259.

Schmolesky, M. T., Wang, Y., Hanes, D. P., Thompson, K. G., Leutgeb, S., Schall, J. D., \& Leventhal, A. G. (1998). Signal timing across the macaque visual system. Journal of Neurophysiology, 79, 3272-3278.

Stanton, G. B., Bruce, C. J., \& Goldberg, M. E. (1995). Topography of projections to posterior cortical areas from the macaque frontal eye fields. Journal of Computational Neurology, 353, 291-305.

Stewart, L., Battelli, L., Walsh, V., \& Cowey, A. (1999). Motion perception and perceptual learning studied by magnetic stimulation. Electroencephalography and Clinical Neurophysiology, Supplement, 51, 334-350.

Stewart, L. M., Walsh, V., \& Rothwell, J. C. (2001). Motor and phosphene thresholds: A transcranial magnetic stimulation correlation study. Neuropsychologia, 39, 415-419.

Talairach, J., \& Tournoux, P. (1988). Co-planar stereotaxic atlas of the buman brain. Stuttgart: Thieme.

Thompson, K. G., Bichot, N. P., \& Schall, J. D. (1997). Dissociation of visual discrimination from saccade programming in macaque frontal eye field. Journal of Neurophysiology, 77, 1046-1050.

Thompson, K. G., Hanes, D. P., Bichot, N. P., \& Schall, J. D. (1996). Perceptual and motor processing stages identified in the activity of macaque frontal eye field neurons during visual search. Journal of Neurophysiology, 76, 4040-4055.

Thompson, K. G., \& Schall, J. D. (1999). The detection of visual signals by macaque frontal eye field during masking. Nature Neuroscience, 2, 283-288.

Walsh, V., \& Pascual-Leone, A. (2003). Transcranial magnetic stimulation: A neurochronometrics of mind. Massachusetts: MIT Press.

Wipfli, M., Felblinger, J., Mosimann, U. P., Hess, C. W., Schlaepfer, T. E., \& Muri, R. M. (2001). Double-pulse transcranial magnetic stimulation over the frontal eye field facilitates triggering of memory-guided saccades. European Journal of Neuroscience, 14, 571-575.

Yousry, T. A., Schmid, U. D., Alkadhi, H., Schmidt, D., Peraud, A., Buettner, A., \& Winkler, P. (1997). Localization of the motor hand area to a knob on the precentral gyrus. A new landmark. Brain, 120, 141-157. 